\title{
Assessing arsenic ecotoxicity in tropical soils for regulatory purposes: Which endpoints are more appropriate?
}

\author{
L.R.G. Guilherme ${ }^{1}$, G.C. Martins ${ }^{1}$, C. Oliveira ${ }^{1}$, E.S. Penido ${ }^{2}$, T. Natal-da-Luz ${ }^{3}$ \& J.P. Sousa ${ }^{3}$ \\ ${ }^{1}$ Department of Soil Science, Federal University of Lavras, Minas Gerais, Brazil \\ ${ }^{2}$ Department of Chemistry, Federal University of Lavras, Minas Gerais, Brazil \\ ${ }^{3}$ Centre for Functional Ecology, Department of Life Sciences, University of Coimbra, Coimbra, Portugal
}

\begin{abstract}
Ecotoxicological tests with plants are often used to help regulators setting soil screening values of many contaminants, arsenic (As) included. Yet, the measurement of a comprehensive set of endpoints in representative plant species is very time-consuming and hard to achieve in a single test. This study evaluated the best-suited endpoints to assess As toxicity and contamination effects in crop plants grown in oxidic soils, with a focus on Tropical agroecosystems. Our aim is to recommend an approach for setting soil screening values that uses arsenic ecotoxicological studies chosen on the basis of the sensitivity and reliability of endpoints in plant growth tests. From the measured endpoints, the most sensitive ones were: first germination count $>$ relative leaf area $>$ total dry mass $>$ germination speed index, while the most reliable endpoints were: first germination count $>$ total dry mass $=$ germination speed index $>$ plant height. The species Phaseolus vulgaris and Zea mays were the most and least sensitive to arsenic toxicity, respectively. The use of extractable As concentrations for toxicity characterization allows estimating more realistic soil screening values for arsenic in Tropical soils.
\end{abstract}

\section{INTRODUCTION}

Arsenic (As) is a metalloid widely distributed throughout Earth, and it is known to be toxic to most living organisms. It has been ranked number one in the ATSDR's Substance Priority List of hazardous substances for the last 20 years, posing the most significant potential threat to human health and the environment. Because of that, arsenic accumulation and effects in plants should be taken into account when evaluating its toxicity.

Different plant species have distinctive capacities to absorb, accumulate, and tolerate As, which also depends on soil properties. Furthermore, arsenic absorption by plants is quite variable, since each species has different levels of metabolic tolerance and detoxification mechanisms to arsenic compounds (Yoon et al., 2015).

For this reason, laboratory ecotoxicological tests using different standard species as test organisms have been used to characterize the risk associated to specific substances in different soils. However, it is not always possible to measure many plants endpoints in a single test. Therefore, it is important to define which endpoints are most relevant to evaluate As toxicity.

Developing ecotoxicological studies for As contributes for the development of a better database to be used in decision-making actions related to environmental issues. Therefore, the objective of this study was to evaluate the best-suited endpoints to assess As toxicity and contamination effects in crop plants, based on the sensitivity and reliability of endpoints in plant growth tests.

For this purpose, eleven endpoints were evaluated in six plant species, which were exposed to gradients of increasing As concentrations in two natural soils and one artificial tropical soil.

\section{METHODS/EXPERIMENTAL}

\subsection{Soil sampling and test plants}

A Red-yellow Latosol - Oxisol $\left(21^{\circ} 17^{\prime} 08^{\prime \prime} \mathrm{E}\right.$, $\left.44^{\circ} 47^{\prime} 43^{\prime \prime} \mathrm{N}\right)$ and a Haplic Cambisol - Inceptsol $\left(21^{\circ} 13^{\prime} 46^{\prime \prime} \mathrm{E}, 44^{\circ} 59^{\prime} 10^{\prime \prime} \mathrm{N}\right)$, and an tropical artificial soil - TAS, which was produced by mixing dry kaolinite clay $(20 \%)$, fine sand $(70 \%)$, and coconut fiber $(10 \%)$, were used in the experiments. Soil samples were air-dried, sieved to $2 \mathrm{~mm}$ and characterized. Maximum water holding capacity was determined as defined by ISO 11274 . Soil As was determined using the Mehlich-1 extractant. The maximum adsorption capacity of each soil was determined as defined by Campos et al. (2007). Arsenic levels were measured by graphite furnace absorption spectroscopy (Perkin Elmer - AAnalyst ${ }^{\mathrm{TM}}$ ). Attributes of the soils are shown in Table 1.

Six commercial crop species were chosen: monocotyledonous: maize (Zea mays), rice (Oryza sativa), sorghum (Sorghum bicolor); and eudicotyledonous: beans (Phaseolus vulgaris), sunflower (Helianthus annuus), and radish (Raphanus sativus). 


\subsection{Greenhouse experimental design}

The experiments were conducted under greenhouse with natural light and ambient temperature $\left(25 \pm 3^{\circ} \mathrm{C}\right)$, controlled by an electronic ventilation system. Tests with plants were based on procedures described in OECD Test $n^{\circ} 208$. Three days prior to experiments, soils were fertilized $(\mathrm{N}=100 \mathrm{mg} ; \mathrm{P}=100 \mathrm{mg} ; \mathrm{K}=50 \mathrm{mg} ; \mathrm{Ca}=37 \mathrm{mg}$; $\mathrm{Mg}=15 \mathrm{mg} ; \mathrm{S}=25 \mathrm{mg} ; \mathrm{B}=0.25 \mathrm{mg} ; \mathrm{Cu}=0.75 \mathrm{mg}$; $\mathrm{Zn}=2.5 \mathrm{mg} ; \mathrm{Mn}=5 \mathrm{mg}$; and $\mathrm{Mo}=0.1 \mathrm{mg})$. The following concentration gradients: $0,8,14.5,26,46.5,84$, 150 and $270 \mathrm{mg} \mathrm{As} \mathrm{kg}^{-1}$ were used to cover soil quality guidelines values adopted in Brazil. The doses were directly added to soils, keeping $50 \%$ of the water holding capacity of each soil. The tests began with seeds sowing and lasted until 21 days after $\geq 50 \%$ of the seeds from control units had germinated. The endpoints considered in each test for analysis of arsenic toxicity were: germination speed index (GSI), final germination count $(\mathrm{FnC})$, total germination (TG), plant survival (PS), completely expanded leaves (CEL), soil plant analysis development (SPAD), relative leaf area (RLA), stem diameter (SD), plant height (PH) and; and total dry mass (TDM). At the end of the experimental period, plants were cut at the base and dried at $60^{\circ} \mathrm{C}$ until constant weight, for the subsequent determination of dry weight and As concentration.

The (total) arsenic concentration for $50 \%$ of effect $\left(\mathrm{EC}_{50}\right)$ was estimated for each endpoint. To evaluate the adequacy of the endpoints, the parameters were characterized according to their sensitivity and reliability. Endpoints were ranked in two sequences for each soil and test species: i) descending order of sensitivity (the lower for higher $\mathrm{EC}_{50}$ value); and, ii) descending order of reliability (the lower for higher amplitude of $95 \%$ confidence intervals of the $\mathrm{EC}_{50}$ estimated). The endpoints with the lower mean ranks were considered the most sensitive or reliable. Therefore, these endpoints were selected for evaluating the contamination effects of As in crop plants. For these selected endpoints, $\mathrm{EC}_{50}$ values were estimated with total and phytoavailable arsenic concentrations measured in soil samples.

\subsection{Chemical analysis of arsenic in soil and plants}

Dried samples were digested using $\mathrm{HNO}_{3}(65 \%)$ in a microwave oven (Mars 5, CEM Corporation, Matthews, NC, USA) for total As contents. Phytoavailable contents were measured by adding $0.5 \mathrm{~g}$ of sample in $5 \mathrm{~mL}$ of a Mehlich- 1 solution $\left(0.05 \mathrm{~mol} \mathrm{~L}^{-1}\right.$ $\left.\mathrm{HCl}+0.0125 \mathrm{~mol} \mathrm{~L}^{-1} \mathrm{H}_{2} \mathrm{SO}_{4}\right)$, followed by shaking $(5 \mathrm{~min})$ and filtration after 16 hours $(0.45-\mu \mathrm{m}$ filter $)$. Arsenic concentrations were determined by atomic absorption spectrophotometry with electrothermal atomization using graphite furnace (Perkin Elmer AAnalyst ${ }^{\text {TM}} 800$, Norwalk, CT, 171 USA).

Certified reference materials containing matrices compatible with the samples were used: plant material 180 BCR-482 No. 638 and for soil samples SRM
Table 1. Physical and chemical properties of soils.

\begin{tabular}{llll}
\hline & ATS & Oxisol & Inceptsol \\
\hline $\mathrm{pH}\left(\mathrm{H}_{2} \mathrm{O}\right)$ & 5.2 & 4.4 & 4.6 \\
$\mathrm{OM} / \%$ & 7.84 & 0.24 & 1.87 \\
$\mathrm{CEC} / \mathrm{cmol}_{c} \mathrm{dm}^{-3}$ & 2.27 & 0.27 & 2.01 \\
$\mathrm{P}-\mathrm{rem} / \mathrm{mg} \mathrm{L}^{-1}$ & 36.1 & 6.84 & 4.31 \\
$\mathrm{As} / \mathrm{mg} \mathrm{kg}^{-1}$ & $<0.01$ & 0.026 & $<0.01$ \\
$\mathrm{Qe} / \mathrm{mg} \mathrm{As} \mathrm{kg}^{-1}$ & nd & 714.3 & 1,667 \\
$\mathrm{WHC} / \%$ & 74.0 & 41.0 & 59.0 \\
$\mathrm{Clay} / \%$ & 19 & 26 & 33 \\
$\mathrm{Silt} / \%$ & 8 & 8 & 66 \\
$\mathrm{Sand} / \%$ & 73 & 66 & 19 \\
$\mathrm{Fe}_{2} \mathrm{O}_{3} / \%$ & 2.86 & 3.84 & 25.1 \\
\hline
\end{tabular}

nd= not detected; Qe = maximum adsorption capacity; $\mathrm{WHC}=$ water holding capacity.

Table 2. Germination and growth endpoints sorted in descending order of sensitivity or reliability and respective average ranks $(\mathrm{Rk})$ for all test species, considering all soils.

\begin{tabular}{lllll}
\hline Sensitivity & & & Reliability & \\
\cline { 5 - 6 } Endpoint & Rk & & Endpoint & Rk \\
\hline FrC & 2.3 & & FrC & 3.9 \\
RLA & 4.3 & & TDM & 4.9 \\
TDM & 4.7 & & GSI & 4.9 \\
GSI & 5.1 & & PH & 5.0 \\
PH & 5.5 & & FnC & 5.3 \\
FnC & 5.6 & & TG & 5.4 \\
TG & 6.7 & & RLA & 6.2 \\
PS & 7.3 & & CEL & 7.0 \\
SD & 7.4 & & PS & 7.2 \\
CEL & 7.5 & & SD & 7.5 \\
SPAD & 9.0 & SPAD & 8.3 \\
\end{tabular}

2711a and SRM 2710a. The recovery rate were $76.5 \%$, $98.2 \%$ and $101 \%$ for BCR-482, SRM $2711 \mathrm{a}$, and SRM $2710 \mathrm{a}$, respectively.

\section{RESULTS AND DISCUSSION}

Considering all soils, the most sensitive endpoints were $\mathrm{FrC}$, RLA, and TDM, while GSI, PH, and FnC had a median sensitivity. SPAD was always the least sensitive endpoint (Table 2).

Germination is the first attribute that may be influenced by contaminants ( $\mathrm{Li}$ et al., 2007). The early germination $(\mathrm{FrC})$ is often the most sensitive endpoint, because some of the defense mechanisms of the plant are still not developed (Liu et al., 2005). Endpoints related to germination ( $\mathrm{FrC}, \mathrm{FnC}$, and $\mathrm{TG})$ had contrasting sensitivity and reliability, as apparently, there are concentrations that only retard germination. After germination, subsequent processes become affected by soil contamination, which reflected in the development of plant and growth endpoints (Srivastava et al., 2013). Another effect of As in plants is related to chlorophyll degradation, but in the present study, this phenomenon did not occur intensively. 
Table 3. Total and phytoavailable arsenic content (respective recoveries over the nominal content) in the soils.

\begin{tabular}{lccc}
\hline \multicolumn{3}{l}{ Total $\left(\mathrm{mg} \mathrm{kg}^{-1}\right)$} & \\
\hline Dose & TAS & Oxisol & Inceptisol \\
\hline 0 & 3.1 & 2.43 & 1.68 \\
8 & $7.18(90 \%)$ & $5.57(70 \%)$ & $7.87(98 \%)$ \\
14.5 & $14.3(99 \%)$ & $12.0(83 \%)$ & $7.47(51 \%)$ \\
26 & $25.3(97 \%)$ & $21.8(84 \%)$ & $22.7(87 \%)$ \\
46.5 & $40.6(87 \%)$ & $40.1(86 \%)$ & $32.3(64 \%)$ \\
84 & $80.4(96 \%)$ & $69.2(82 \%)$ & $87.4(104 \%)$ \\
150 & $148(99 \%)$ & $134(89 \%)$ & $113(76 \%)$ \\
270 & $260(97 \%)$ & $247(92 \%)$ & $257(95 \%)$ \\
\hline
\end{tabular}

Phytoavailable $\left(\mathrm{mg} \mathrm{kg}^{-1}\right)$

\begin{tabular}{lcll}
\hline Dose & TAS & Oxisol & Inceptisol \\
\hline 0 & 0.33 & 0.37 & 0.21 \\
8 & $1.17(15 \%)$ & $0.64(8 \%)$ & $0.10(1 \%)$ \\
14.5 & $2.82(19 \%)$ & $1.72(12 \%)$ & $0.21(1 \%)$ \\
26 & $4.62(18 \%)$ & $3.34(13 \%)$ & $0.48(2 \%)$ \\
46.5 & $18.8(40 \%)$ & $7.47(16 \%)$ & $1.17(2 \%)$ \\
84 & $29.3(35 \%)$ & $14.8(15 \%)$ & $1.42(2 \%)$ \\
150 & $56.9(38 \%)$ & $31.6(21 \%)$ & $3.69(2 \%)$ \\
270 & $145(54 \%)$ & $78.4(29 \%)$ & $11.6(4 \%)$ \\
\hline
\end{tabular}

Our data showed a tendency of smaller confidence intervals in $\mathrm{EC}_{50}$ values estimated by $\mathrm{FrC}$, followed by $\mathrm{TDM}=\mathrm{GSI}, \mathrm{PH}$, and $\mathrm{FnC}$ endpoints. The $\mathrm{EC}_{50}$ values estimated by SPAD, SD, and PS had generally the lowest reliability (Table 2).

Total arsenic concentrations had good recoveries (Table 3), which confirms that that the test species were exposed to a broad concentration gradient. Regarding phytoavailable As concentrations, the highest recovery percentages were observed for the TAS and the lowest for the Inceptisol. The pattern of availability observed in each test soil was related to the specific attributes of each one (Table 1) and corroborates with the relative toxicities found among the three tested soils (Table 4).

The estimated $\mathrm{EC}_{50}$ using total As concentrations show the highest differences among contrasting soils, while the lowest differences were observed for $\mathrm{EC}_{50}$ estimated using phytoavailable As concentrations. These results reinforce the use of available levels for regulatory purposes, because they reduce differences among toxicity data on contrasting soils.

From the species studied, P. vulgaris was the most sensitive and $Z$. mays was the least sensitive to arsenic. Both species also accumulated less arsenic in the tissues (Table 5). The species $H$. annuus and $R$. sativus had the highest arsenic accumulation, which is a reflex of adaptive strategies to the contaminant.

\section{CONCLUSIONS}

The most sensitive endpoints were: first germination count $>$ relative leaf area $>$ total dry mass $>$ germination speed index, while the most reliable endpoints were: first germination count $>$ total dry mass $=$ germination
Table 4. EC50 values (with corresponding 95\% confidence intervals) for the effects on total dry mass of the test species cultivated in contrasting soils. EC50 estimations were based on total and phytoavailable arsenic concentrations and are expressed in $\mathrm{mg} \mathrm{kg}^{-1}$.

Total

\begin{tabular}{llll}
\hline & ATS & Inceptisol & $\Delta$ \\
\hline Rice & $24.0(19.6-28.5)$ & $189(156-223)$ & 165 \\
Maize & $49.9(24.5-75.3)$ & $>257$ & 207 \\
Sorghum & $38.9(28.6-49.3)$ & $183(153-213)$ & 144 \\
Common-bean & $<7.18$ & $46.7(38.8-54.7)$ & 39.5 \\
Sunflower & $27.1(21.2-33.0)$ & $>257$ & 229 \\
Radish & $41.9(36.7-47.2)$ & $>257$ & 215 \\
\hline
\end{tabular}

Phytoavailable

\begin{tabular}{llll}
\hline & ATS & Inceptisol & $\Delta$ \\
\hline Rice & $4.45(3.63-5.28)$ & $7.80(6.10-9.51)$ & 3.30 \\
Maize & $22.8(15.8-29.7)$ & $>11.6$ & -11.2 \\
Sorghum & $8.55(3.30-13.7)$ & $6.94(5.24-8.64)$ & -1.61 \\
Common-bean & $<1.17$ & $1.34(1.24-1.45)$ & 0.17 \\
Sunflower & $5.69(4.48-6.89)$ & $>11.6$ & 5.91 \\
Radish & $19.2(17.1-21.3)$ & $>11.6$ & -7.60 \\
\hline
\end{tabular}

Note: $\Delta=\mathrm{EC}_{50}$ (Inceptisol) $-\mathrm{EC}_{50}(\mathrm{ATS})$.

Table 5. Arsenic content in the shoot of the species cultivated at the dose $26 \mathrm{mg} \mathrm{As} \mathrm{kg}^{-1}$. The values are expressed in $\mathrm{mg} \mathrm{kg}^{-1}$.

\begin{tabular}{llll}
\hline & ATS & Oxisol & Inceptisol \\
\hline Rice & $24.9 \pm 0.13$ & $3.09 \pm 0.58$ & $0.89 \pm 0.09$ \\
Maize & $2.54 \pm 2.72$ & $0.65 \pm 0.14$ & $0.87 \pm 0.07$ \\
Sorghum & $1.95 \pm 0.18$ & $1.22 \pm 0.19$ & $0.81 \pm 0.16$ \\
Beans & n.d. & $1.72 \pm 0.54$ & $0.66 \pm 0.31$ \\
Sunflower & $13.9 \pm 2.45$ & $5.69 \pm 0.68$ & $0.79 \pm 0.15$ \\
Radish & $14.1 \pm 1.71$ & $10.3 \pm 1.17$ & $1.81 \pm 1.04$ \\
\hline As-Total & $25.3 \pm 1.23$ & $21.8 \pm 1.13$ & $22.7 \pm 0.41$ \\
\hline As-Phytoavailable & $4.62 \pm 1.83$ & $3.34 \pm 0.35$ & $0.48 \pm 0.10$ \\
\hline
\end{tabular}

speed index $>$ plant height. Amongst the evaluated plant species, $P$. vulgaris and $Z$. mays were the most and least sensitive to arsenic toxicity, respectively. The use of extractable As concentrations for toxicity characterization allows estimating more realistic toxic values among different soils.

\section{ACKNOWLEDGEMENTS}

The authors thank the funding agencies Minas Gerais State Research Foundation (FAPEMIG), National Council for Scientific and Technological Development (CNPq Grant\# 140081/2014-3), and Coordination for the Improvement of Higher Education Personnel 
(CAPES Grant\# BEX3204/15-4) for the financial support.

\section{REFERENCES}

Campos, M.L., Guilherme, L.R.G., Lopes, R.S., Antunes, A.S., Marques, J.J.G. de S. e M. \& Curi, N. 2007. Teor e capacidade máxima de adsorção de arsênio em Latossolos brasileiros. Rev. Bras. Ciência do Solo 31: 1311-1318.

Li, C., Feng, S., Shao, Y., Jiang, L., Lu, X. \& Hou, X. 2007. Effects of arsenic on seed germination and physiological activities of wheat seedlings. J. Environ. Sci. 19: 725-732.
Liu, X., Zhang, S., Shan, X. \& Zhu, Y.G. 2005. Toxicity of arsenate and arsenite on germination, seedling growth and amylolytic activity of wheat. Chemosphere 61: 293-301.

Srivastava, S., Akkarakaran, J.J., Suprasanna, P. \& D'Souza, S.F. 2013. Response of adenine and pyridine metabolism during germination and early seedling growth under arsenic stress in Brassica juncea. Acta Physiol. Plant 35: 1081-1091.

Yoon, Y., Lee, W.M. \& An, Y.J. 2015. Phytotoxicity of arsenic compounds on crop plant seedlings. Environ. Sci. Pollut. Res. 22: 11047-11056. 